\title{
Midshipmen Learn Materials Failure Analysis and Prevention through Hands-On Lab in Course Elective
}

The engineering student would like to avoid failure and finds it difficult to believe that any aspect of engineering can have negative consequences. An experienced engineer knows that the best successes often stem from failure and that success alone does not teach much. In disasters like the Challenger explosion, the Thresher sinking, or the Chernobyl accident, scientists and engineers hope to gain insight into preventing future failures. At the U.S. Naval Academy, Materials Failures Analysis and Prevention is an elective course offered in the materials and mechanics tracks of the Mechanical Engineering Department. It is designed to educate Naval engineers in component failure investigation. The goal of this course is to strengthen the analytical and design skills of the engineering students and to assure that they derive success from failure. Based on the determined mode of failure of a component, corrective action, especially in the application of materials, can be incorporated back into the design or redesign of the component to prevent similar failures.

The course involves hands-on laboratory experience as well as lecture. The students consider a number of specific topics and practical case studies, organized according to classification by analysis technique and failure mode. Initial discussions center on more notorious cases such as the Titanic sinking, the Tacoma Narrows Bridge collapse, and the brittle hull failure of the World War II Liberty ships. Background material is obtained from the large number of reference texts available in the Naval Academy library. A seminar approach in the classroom is utilized, and the students are expected to discuss selected readings as if they are the investigative engineers. Written assignments based on the readings are required. A number of laboratories conducted during the course are designed to provide the engineer with hands-on experience and the necessary skills to investigate component failure. The student learns nondestructive evaluation techniques and optical and electron microscopy as well as mechanical testing and processing techniques to replicate failure scenarios.

Each student or team of students is responsible for selecting a failure analysis project early in the semester. In one example, a team of students chose as their topic the failure of a compressor studbolt supplied by a company. The studbolt, consisting of a low alloy steel 3OCND8, had

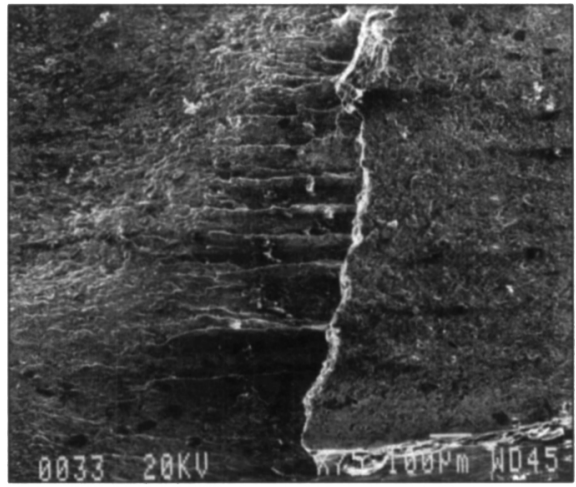

\begin{abstract}
Students at the U.S. Naval Academy conduct a laboratory investigation to determine the cause of failure of a compressor studbolt. Shown is a scanning electron microscope image of a studbolt consisting of a low alloy steel, 3OCND8, showing beachmarks indicating brittle fatigue.
\end{abstract}

recently failed during use in a liquid ring hydrogen compressor. The studbolt had a tensile strength of $1230 \mathrm{MPa}$, yield strength of $1030 \mathrm{MPa}$, a $10 \%$ elongation, and hydrostatic test pressure of 91.14 psig. Within a three-week time span, the students provided a brief description of their topic along with a detailed test plan for approval before pursuing the investigation.

The team then conducted a laboratory investigation to determine the cause of failure, utilizing technical support. They proceeded in a logical manner in which they first applied visual inspection. At this stage the team determined that the fracture surface included plateaus that were indicative of brittle fracture while a deformed ridge suggested ductile fracture. Scanning electron microscopy was used to confirm that a mixed mode of fracture indicative of reversed bending fatigue was present. The team also pursued optical microscopy, a hardness test, and chemical analysis. By the sixth week of the semester, the team presented its progress report to the class, detailing the component history and justifying the experimental route taken to prove cause and mode.

In the 12th week, the team gave a formal presentation to the engineering faculty, local failure analysis experts, and interested guests. The team received suggestions and the instructor's corrections based on the presentation and revised the report. At the end of the semester, rather than a final exam, the team provided a poster of the project. In this case study, the students determined that the cause of the studbolt failure was not material-related or designrelated, but due to an operational error: improper pre-loading of the bolt. Along with recommendations to pre-load the bolt accurately, the team also suggested using bolts made of AISI 4340 . The students said that the bolts made of $30 \mathrm{CND} 8$ are obscure

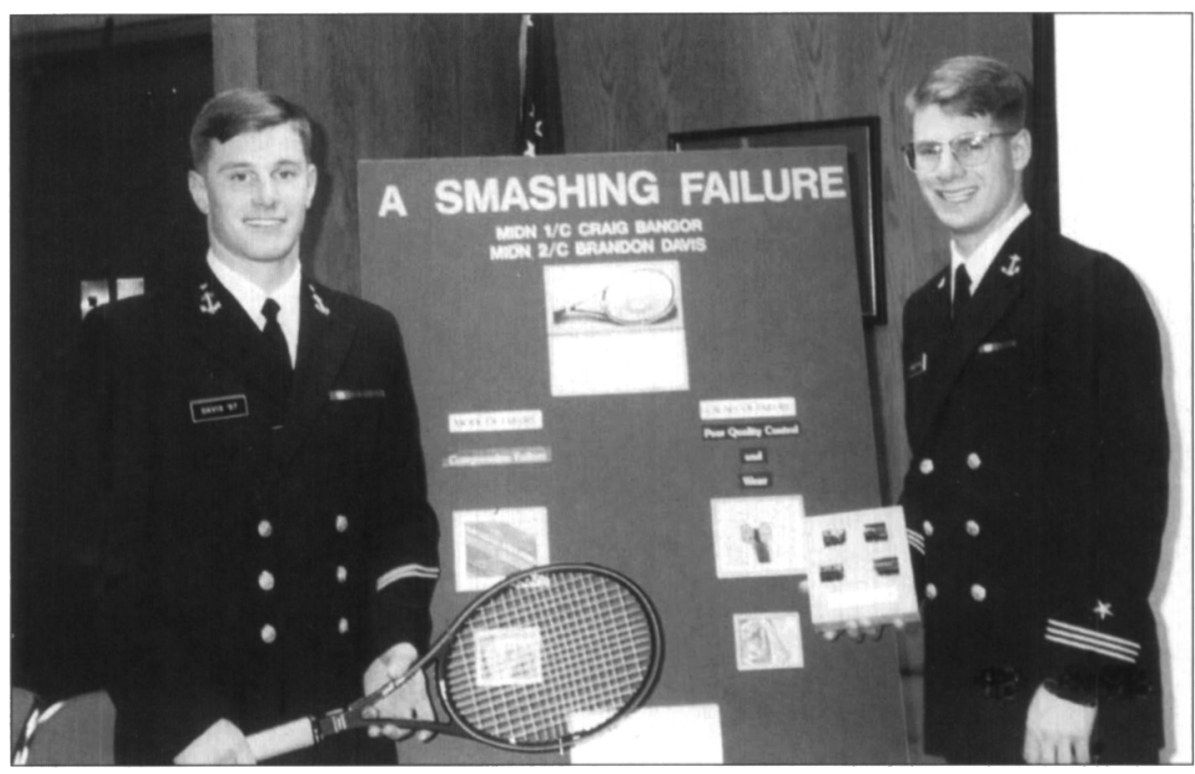

In place of a final exam, Midshipmen present their posters at the end of the semester. 
and difficult to replace, while the alternative bolts have similar specifications and are much more common and easier to obtain.

Midshipmen's failure analysis projects have included investigations into failed components such as an aluminum baseball bat, a piston bolt, a pillow block bearing, a spinnaker pole, a javelin, a tennis racket, a prosthetic knee implant, a tubular turnbuckle, an end mill, a combustion liner, an automobile crankshaft, a marine blower, a Mars pathfinder component, as well as assorted aircraft components. The students participate in a poster contest held at the end of the semester in which their projects are judged on technical content and aesthetic presentation. Given a failed material component, the students should be able to identify possible modes of failure and outline experimental tasks and inspection methods required to select the correct mode. They should collect all necessary facts and information to recre-

Education Exchange highlights experiences of scientists and engineers with local schools $(\mathrm{K}-12)$, community programs, and university programs, along with helpful hints and resources. If you would like to share your own involvement in science education, contact MRS Bulletin, Materials Research Society, 506 Keystone Drive, Warrendale, PA 15086-7573 USA; fax 724-779-8313; e-mail Bulletin@mrs.org. ate the environmental factors, operator errors, design flaws, and processing effects or maintenance mistakes that may have contributed to the failure of the component. They must be able to present their analysis in clear and technically correct terms, understand a broad range of investigation techniques used by engineers to characterize materials failures, and make competent decisions on materials selection based on designed operating and environmental conditions.

ANGELA L. MORAN

Angela L. Moran is an associate professor in the Department of Mechanical Engineering in the Division of Engineering and Weapons at the U.S. Naval Academy. She can be reached at tel. 410-293-6534 or fax 410-293-2591.

\section{Materials MicroWorld}

Enter the
World of
Materials the
Fun Way

\section{www.mrs.org/microworld/}

\begin{abstract}
What is Materials MicroWorld?
The Materials Research Society (MRS) is planning to develop and evaluate a nationally traveling science exhibition, Materials MicroWorld, that promotes public understanding of basic scientific principles, issues, and trends in materials research. Two exhibit versions ( 5000 s.f. and 1500 s.f.) are being planned to serve large and small science centers nationwide. An accompanying array of educational materials and training videos will enable museums to tailor exhibit-related programming to suit the needs of audiences and the capabilities of staff. The educational component includes development of an electronic Best of Materials Science Activities booklet to be published on the MRS website.

Materials MicroWorld aims to present the basic principles, issues, and trends of materials research to the general public; develop new links with informal science education; introduce students to materials science careers; and inform citizens about the pivotal importance and wide applicability of materials science research.
\end{abstract}

\section{MRS Headquarters Lobby Displays}

A set of interactive materials science displays resides in the lobby of the Materials Research Society headquarters building in Warrendale, Pennsylvania. The displays were specially designed and constructed for MRS with input from a task force of materials scientists. The displays are designed to be educational for people of all ages and for scientists and nonscientists alike. The interactive displays are examples of the type of exhibits that will be developed for the MicroWorld project.

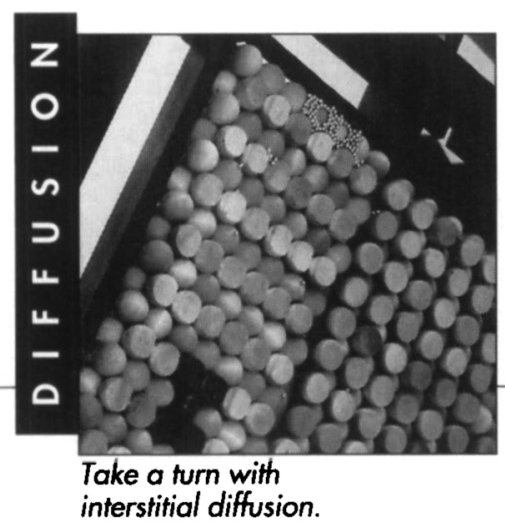

interstitial diffusion.
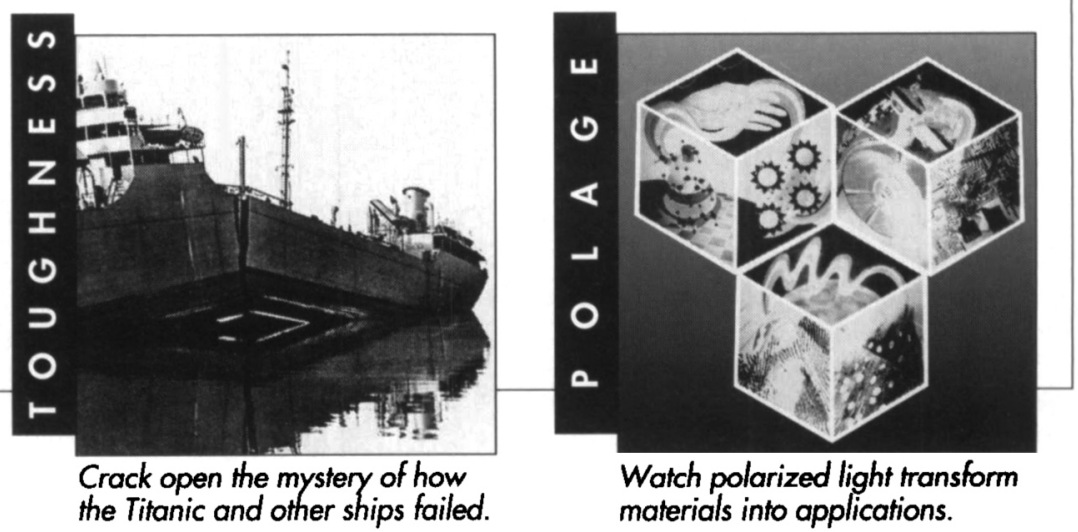


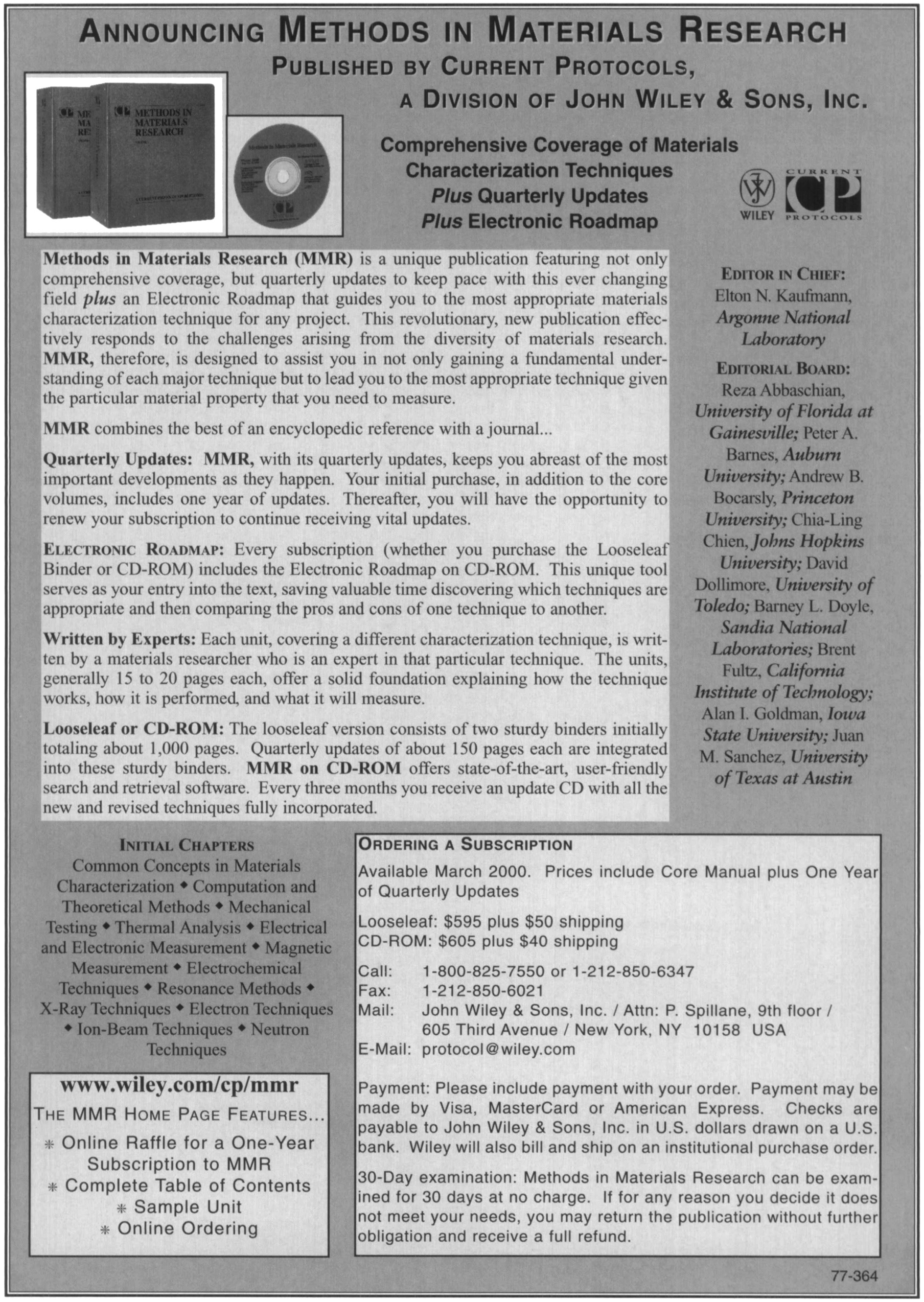

